\title{
Teoria do capital social e o cluster têxtil de Blumenau/SC: um estudo de caso das empresas e instituições locais
}

Graziela dos Santos Bento ${ }^{1}$ Ronaldo Leão de Miranda ${ }^{2}$ Mohamed $\mathrm{Amal}^{3}$

Submissão: $26 / 05 / 2021$

Aceite: $11 / 07 / 2021$

\section{Resumo}

O propósito deste artigo é compreender os benefícios gerados entre os sujeitos que compõem o cluster têxtil de Blumenau, nas dimensões estrutural, relacional e cognitiva do capital social. Por meio de entrevistas com gestores de empresas e instituições, foram identificadas as vantagens do cluster e os ganhos individuais e coletivos do relacionamento entre os agentes. Os benefícios mais relatados foram disponibilidade de mão-de-obra qualificada, acesso facilitado a fornecedores/insumos, participação em núcleos de inovação da Associação Empresarial local e acesso a cursos e treinamentos especializados. Há também indicações de clientes e fornecedores potenciais em feiras especializadas, evidências de compartilhamento do conhecimento, organização de eventos comerciais e garantia de conformidade entre os programas de treinamento oferecidos pelas instituições de ensino e as expectativas das empresas. Por outro lado, aspectos como falta acesso às informações de outras empresas para benchmarking, melhoria da imagem das empresas e acesso aos mercados externos podem ser melhorados.

Palavras-chaves: Capital social. Clusters. Instituições locais. Têxtil.

\section{Social capital theory and the textile cluster of Blumenau-SC: a case study of local companies and institutions}

\begin{abstract}
This article aims to understand the benefits generated between the subjects that compose the Blumenau textile cluster, classified in the structural, relational, and cognitive dimensions of social capital. We identified the advantages of the cluster and the individual and collective gains in the relationship between agents through interviews with managers of companies and institutions. The most reported benefits were the availability of qualified labor, easier access to suppliers/inputs, participation in innovation centers of the local Business Association, and access to specialized courses and training. There are also indications of potential customers and suppliers at specialized fairs, evidence of knowledge sharing, organization of commercial events, and the guarantee of conformity between the training programs offered by educational institutions and the expectations of companies. On the other hand, aspects such as lack of access to information from other companies for benchmarking, improvement of the companies' image, and access to foreign markets can be improved.
\end{abstract}

Keywords: Social Capital. Clusters. Local institutions. Textile.

\section{Introdução}

Clusters são aglomerações geográficas de empresas e instituições interconectadas que podem melhorar o desempenho das empresas ao disponibilizar e formar mão-de-obra qualificada, aumentar o acesso a fornecedores e insumos, aumentar o acesso a bens públicos e

\footnotetext{
${ }^{1}$ Doutoranda em Ciências Contábeis e Administração (FURB). Professora na Fundação Universidade Regional de Blumenau (FURB). https://orcid.org/0000-0002-1488-2126 E-mail: grazithata@gmail.com

2 Doutorando em Ciências Contábeis e Administração (FURB). Bolsista da FAPESC. https://orcid.org/0000-00016778-2463 E-mail: ronaldo leaomiranda@hotmail.com

3 Pós-Doutorado em Desenvolvimento Sustentável (Columbia University/USA). Doutorado em Engenharia de Produção (UFSC). Professor do Programa de Pós-Graduação em Administração da Fundação Universidade Regional de Blumenau (FURB). https://orcid.org/0000-0001-7851-267X E-mail: amal@furb.br
} 
infraestrutura e promover aplicação mais eficiente de benchmarking (PORTER, 1998). A teoria do capital social ajuda a demonstrar o papel das redes sociais de uma empresa como forma de gerar vantagens competitivas, desenvolvendo relações colaborativas com outros atores, com o objetivo de criar acesso a recursos que podem ser mobilizados conforme os interesses da organização (BURT, 2009). Dessa forma, o capital social deriva do acesso a recursos coletivos, disponibilizados por meio de relações sociais, no qual tem como principal nível de analise o indivíduo, grupos, organizações e comunidade (GRANOVETTER, 1992). O autor ainda destaca que, uma rede de relacionamento que envolve universidade, empresas e governo contribui para a inovação e o desenvolvimento econômico.

A partir do relacionamento entre esses agentes, ocorre o transbordamento de conhecimentos formais e informais (GRESS, 2011). Diante disso, essas afirmações nos levam a algumas reflexões: As empresas que fazem parte de um cluster percebem esses benefícios? Quais as instituições que possuem maior relacionamento com as empresas do cluster? Que iniciativas elas oferecem ao cluster? Vários estudos sobre clusters foram realizados no Brasil, em um deles, Macke, Vallejos, Faccin e Genari (2013), analisaram o capital social na competitividade de redes colaborativas da indústria de vinhos brasileira. Já Hoffmann, Lopes e Medeiros (2014) verificaram como o conhecimento é transferido entre pequenas empresas que operam em clusters industriais, e como este recurso competitivo circula e é acessado, no cluster que lidera as exportações brasileiras de móveis. E, em um terceiro estudo encontrado, Hoffmann, Bandeirade-Mello e Molina-Morales (2011), analisaram se a inovação da empresa é influenciada pela transferência de conhecimento entre empresas de clusters no Brasil.

Em se tratando do cluster têxtil, estudos analisaram clusters têxteis em diferentes regiões, como Valência (MOLINA-MORALES; EXPÓSITO-LANGA, 2012; VICEDO; VICEDO, 2011); Taiwan (CHEN; HAGA; FONG, 2016); São Paulo (FARINA et al., 2017); Ilhota (MONDINI; AMAL; GOMES, 2016). Sohn et al. (2014), compararam os canais de aprendizagem dos clusters têxteis e de vestuário de Santa Catarina, no Brasil, e da região Norte de Portugal. A pesquisa revelou a necessidade de uma maior aproximação entre empresas com universidades e instituições tecnológicas no Brasil, pois praticamente não foram identificadas parcerias para o desenvolvimento de projetos colaborativos e inovadores. Até a presente data, não foi possível identificar nas buscas realizadas pesquisas no cluster têxtil na região de Blumenau que envolvesse a relação das empresas com instituições locais, e que usasse como base a Teoria do capital social. 
Diante destes breves estudos analisados, a lacuna de pesquisa encontrada diz respeito, a como as empresas do cluster têxtil de Blumenau e região se beneficiam das externalidades geradas pela aproximação geográfica, bem como das relações que existe entre outras empresas e instituições locais. Neste contexto, emerge a seguinte pergunta de pesquisa: Como as dimensões estrutural, relacional e cognitiva do capital social geram benefícios para os sujeitos que compõem o cluster têxtil de Blumenau? O propósito do presente artigo é compreender os benefícios gerados entre os sujeitos que compõem o cluster têxtil de Blumenau, nas dimensões estrutural, relacional e cognitiva do capital social.

O estudo traz algumas contribuições. Como contribuição social, o estudo visa mostrar à sociedade civil que as formas de relacionamento e os benefícios gerados ao cluster têxtil e de confecção pelo seu capital social ajudam a melhorar o desenvolvimento regional. Ainda, contribui com a literatura de cluster ao identificar os benefícios gerados pelo capital social e pelas externalidades geradas no cluster têxtil de Blumenau, mapeando as relações entre empresas e instituições do cluster. Finalmente, os resultados permitem que gestores tanto de empresas como instituições do cluster avaliem oportunidades de fortalecimento das relações e possíveis ganhos por meio do cluster.

A partir desta breve introdução, parte-se para a fundamentação teórica, segunda parte deste estudo, visto que o artigo está dividido em seis partes, introdução, fundamentação teórica, procedimentos metodológicos, análise e discussão dos resultados e por fim as considerações finais e referências.

\section{Fundamentação teórica}

\subsection{Capital social}

O capital social é um termo amplo que engloba as normas e redes que facilitam ações coletivas para benefícios mútuos (Woolcock, 1998). Os atores estabelecem relações propositalmente e continuam com elas enquanto continuam fornecem vantagens. Certos tipos de estrutura social, no entanto, são especialmente importantes para facilitar algumas formas de capital social (COLEMAN,1988). Por exemplo, o relacionamento entre universidade, empresas e governo contribui para a inovação e o desenvolvimento econômico. A partir do relacionamento entre esses agentes, ocorre o transbordamento de conhecimentos formais e informais (GRESS, 2011). Este modelo é chamado de hélice-tripla. Para Etzkowitz e Leydesdorff (2000), a maioria dos países e regiões atualmente aplicam o modelo de hélice-tripla com o objetivo comum de realizar um ambiente inovador composto por universidades, iniciativas para o desenvolvimento 
econômico baseado em conhecimento e alianças estratégicas entre empresas de pequeno e grande porte de diversas áreas, laboratórios e grupos de pesquisa acadêmica.

Dessa forma, o capital social tem um importante papel no desenvolvimento da região, sendo um conjunto de recursos reais e potenciais disponíveis na estrutura de relacionamentos entre os agentes envolvidos ( BOURDIEU, 1988; ARAGÓN et al., 2014). Esse tipo de capital deriva do acesso a recursos coletivos, disponibilizados por meio de relações sociais (GRANOVETTER, 1992). Ao contrário de outras formas de capital, como o econômico, por exemplo, o capital social não esgota em função do uso, ao contrário, esgota-se caso não seja utilizado (BOLLIER, 2001).

Assim, a teoria do capital social pode ser utilizada para demonstrar o papel das redes sociais de uma empresa como forma de gerar vantagens competitivas, desenvolvendo relações colaborativas com outros atores, com o objetivo de criar acesso a recursos que podem ser mobilizados conforme os interesses da organização (BURT, 2009). Para Nahapiet e Ghoshal (1998), o capital social é definido a partir de três dimensões distintas, mas que estão interrelacionadas, considerando a integração de seus diferentes enfoques: dimensão estrutural, dimensão relacional e dimensão cognitiva.

\subsection{Dimensão estrutural e clusters}

A primeira dimensão do capital social, a dimensão estrutural, refere-se ao padrão geral de conexões sociais entre os atores, ou seja, as estruturas presentes em um determinado ambiente. Ambientes nos quais a existência de clusters é perceptível são bons exemplos da dimensão estrutural. Clusters são aglomerações de indústrias especializadas em localidades específicas. Marshall (1982), define essas aglomerações como distritos industriais e afirma que as aglomerações podem ajudar as empresas, particularmente as pequenas, a obter vantagens em uma mesma área geográfica, formando uma atmosfera industrial que influencia mutuamente o sistema socioeconómico. Ainda segundo Marshall (1982), essas vantagens não seriam verificadas caso eles estivessem atuando em regiões distantes umas das outras.

Além disso, Rodrigues et al. (2012), ressalta que o distrito Marshalliano destaca o papel dos trabalhadores como disseminadores de informação e experiência, dentro do distrito, e dá importância tanto para as relações comerciais como para aspectos socioculturais. Na visão de Beccatini (1994), o distrito industrial é uma entidade sócio territorial caracterizada pela copresença ativa, numa área territorial circunscrita, natural e historicamente delimitada, de uma comunidade de pessoas e de uma população de empresas industriais. 
Porter (1998), aprimora os conceitos anteriores, afirmando que clusters são aglomerações geográficas de empresas e instituições interconectadas, como por exemplo, indústrias, fornecedores de insumos e serviços, provedores de infraestrutura, canais de distribuição, clientes e fabricantes de produtos complementares que competem, mas também cooperam. Ainda segundo Porter (1998), os clusters podem incluir também instituições governamentais e outras, como universidades, agências de definição de padrões, conselheiros, provedores de treinamento vocacional e associações comerciais que fornecem treinamento especializado, educação, informação, pesquisa e suporte técnico. Essas instituições melhoram o desempenho das empresas ao disponibilizar e formar mão-de-obra qualificada, aumentar o acesso a fornecedores e insumos, aumentar o acesso a bens públicos e infraestrutura e promover aplicação mais eficiente de benchmarking.

Estudos desenvolvidos no Brasil, cunharam o termo Arranjos Produtivos Locais (APLs), os quais possuem atributos como: proximidade geográfica, especialização setorial, predominância de Pequenas e Médias Empresas (PMEs), colaboração estreita e competição entre firmas baseada na inovação, confiança e identidade socioeconômica, organizações que apoiam prestadores de serviços em comum, promoção entre governos regionais e estaduais (CAMPOS; PAULA, 2008). Assim, pode-se conceituar os APLs como aglomerações territoriais de agentes econômicos, políticos e sociais, que desenvolvem atividades econômicas específicas, apresentam vínculos, interações, aprendizado e cooperação entre seus atores, podendo resultar em incremento da capacidade inovativa e produtiva por meio da transmissão do conhecimento (RODRIGUES et al., 2012). Assim, desenvolve-se a primeira proposição teórica deste estudo:

P1 - Empresas inseridas em um cluster possuem acesso facilitado às estruturas disponíveis no ambiente, como mão-de-obra qualificada, fornecedores e infraestrutura logística.

\subsection{Dimensão relacional e instituições do cluster}

A segunda dimensão do capital social é a dimensão relacional, que trata dos ativos criados e impulsionados por imersões em relacionamentos específicos, sendo que, tal dimensão aponta para os relacionamentos entre os indivíduos (NAHAPIET; GHOSHAL, 1998). Neste sentido, Tsai e Ghoshal (1998), destacam que o capital social engloba muitos aspectos de um contexto social, sendo eles: os laços sociais, as relações de confiança e os sistemas de valores, na qual facilitam as ações dos indivíduos inseridos no dado contexto. Pittaway et al. (2004) afirmam que as redes melhoram o acesso ao conhecimento. Além disso, a confiança e reciprocidade gerada pela 
interação social, facilitam a transferência de conhecimento. A ideia por trás da construção das redes de hélice tripla é encorajar os arranjos de colaboração, permitindo que os agentes das empresas, da universidade e do governo se encontrem e trocam conhecimento. Elvekrok et al. (2018), investigaram o valor das redes regionais de hélice tripla, indicando que os principais benefícios da participação da rede são o aumento do acesso ao conhecimento e a melhoria da capacidade para enfrentar os desafios.

Nesse sentido, instituições como associações locais podem ser mecanismos importantes para estimular a cooperação entre firmas para maior competitividade, sejam elas específicas a um determinado setor, câmaras de comércio ou até mesmo clubes de negócios (NEWBERY et al., 2016). Tomlinson, Robert e Branston (2017), verificaram a importância do trabalho em rede e da participação ativa nos aspectos associativos da economia local. Para eles, a vinculação a uma associação empresarial local oferece uma oportunidade de engajar com outros atores e seus membros assumem um papel proeminente em comitês e reuniões que podem exercer uma influência significativa sobre a política do distrito.

Dessa forma, considera-se que as características tradicionais da "economia associativa", como o capital social e a rede local, são particularmente importantes para facilitar o envolvimento democrático local, sendo as associações empresariais locais as principais esferas de influência. Essas associações conduzem para o engajamento local, com membros ativos frequentemente e capazes de exercer influência sobre as iniciativas políticas de todo o distrito (SÖLVELL; WILLIAMS, 2013). A partir desse contexto, formula-se a segunda proposição deste estudo:

P2 - Empresas que possuem relacionamento com instituições locais possuem acesso facilitado a indicações de clientes e fornecedores, além do compartilhamento de conhecimento e aconselhamento técnico e jurídico, fomentando a inovação.

\subsection{Dimensão cognitiva e instituições do cluster}

As associações e organizações que compõem o cluster também contribuem para sua governança. A governança de clusters significa as ações coletivas de várias partes interessadas (incluindo universidades e institutos de pesquisa, grandes e pequenas empresas, governos e outras agências de apoio) para promover o cluster e desenvolver uma vantagem competitiva sustentável. Essas organizações podem auxiliar na criação da identidade e atratividade do cluster, preencher lacunas de inovação em produtos e processos e apoiar o desenvolvimento de políticas 
no cluster (SÖLVELL; WILLIAMS, 2013). A existência dessas organizações de suporte afeta significativamente a estrutura das redes de cluster, aumentando os laços potenciais das empresas ao reduzir a distância entre os atores, melhorando assim suas relações em termos de proximidade, especialmente quando o conhecimento tecnológico está envolvido (MOLINAMORALES; MARTÍNEZ-CHÁFER, 2014).

Um outro objetivo comum dos clusters é o desenvolvimento de iniciativas de cluster que refletem colaborações organizadas entre atores do setor público e privado para aumentar as vantagens competitivas dos clusters (LINDQVIST et al., 2013). Essas iniciativas são esforços organizados para aumentar o crescimento e a competitividade de clusters em uma região, envolvendo as empresas de um cluster, o governo e ou instituições de pesquisa (SÖLVELL; LINDQVIST; KETELS, 2003). Existem políticas claras nos campos de inovação, regiões e indústrias, usando clusters organizados como ferramentas políticas para aumentar a inovação, o crescimento e a competitividade. Essas políticas definem as regras do jogo e selecionam certas formas e estratégias de clusters (LINDQVIST et al., 2013).

As organizações de clusters também desempenham um papel cada vez mais importante nas políticas governamentais para atrair investimento estrangeiro direto, afetando o desenvolvimento regional. As principais políticas defendidas são as seguintes: fornecimento de infraestrutura logística; criação e de instituições pró-mercado; políticas não discricionárias; redução da alíquota tributária estatutária; incentivos às universidades e centros de pesquisa (FARIA, 2016). Essas são as características da terceira dimensão do capital social, a dimensão cognitiva. Essa dimensão se refere a recursos que fornecem representações, interpretações e sistemas de significados compartilhados entre os atores, ou seja, trata dos interesses comuns desses indivíduos (DE MELLO et al.,2015), derivando-se a terceira proposição deste estudo: P3 Empresas que possuem relacionamento com instituições locais beneficiam-se de ações coletivas para desenvolvimento e promoção do cluster.

É importante esclarecer que o fato de empresas cooperarem no cluster não significa que não exista competição. A coopetição envolve o paradoxo da busca simultânea de competição e cooperação com firmas semelhantes no mesmo campo ou indústria (NALEBUFF; BRANDENBURGER, 1996). Sendo assim, o Modelo teórico proposto neste estudo é apresentado na figura 1. 
Figura 1 - Modelo teórico de capital social

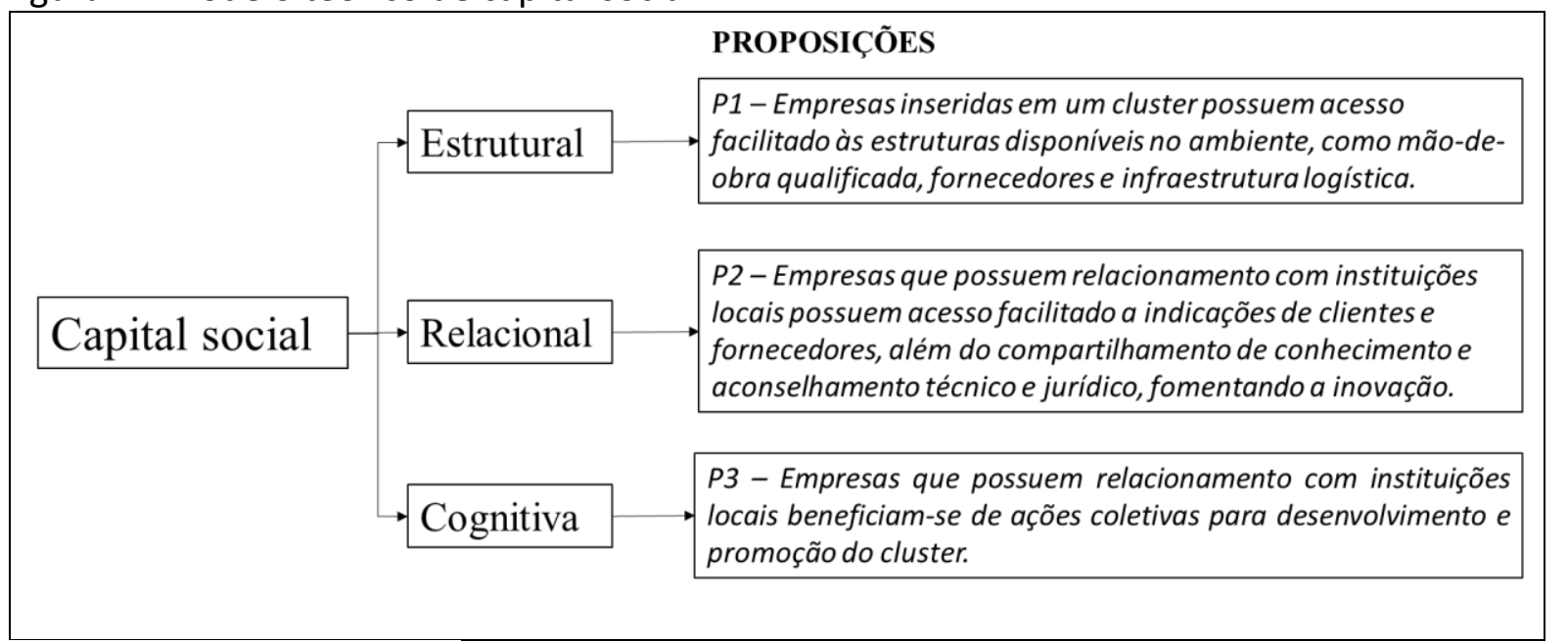

Fonte: Dados da pesquisa (2019).

Apesar dos benefícios inerentes à colaboração no cluster, tensões podem emergir, pois pode ser difícil para as empresas equilibrar a hostilidade inerente à competição e a cordialidade que a cooperação implica, inclusive gerenciando a contradição entre a criação de valor compartilhado e a apropriação do valor privado. Mathews (2018), encontrou muitas formas de cooperação em seu estudo com pequenas e médias empresas francesas que fornecem serviços para a indústria de relógios suíços.

As práticas de colaboração mais frequentes são o empréstimo de ferramentas e equipamentos, o compartilhamento de orientações sobre como fabricar uma determinada peça, compra de matérias-primas a preços mais baixos por meio de associações, união de empresas para obtenção de contratos maiores e posterior redistribuição do trabalho entre elas. No entanto, em se tratando de clientes, nenhum entrevistado mencionou a intenção de combinar suas forças de vendas ou compartilhar informações.

Sendo assim, diante da exposição teórica, esta pesquisa pretende responder a seguinte questão de pesquisa, quais são os benefícios gerados aos sujeitos do cluster têxtil e de confecção da região de Blumenau, a partir das relações entre as empresas e as instituições locais, sob uma perspectiva da teoria do capital social?

\section{Procedimentos metodológicos}

Metodologicamente trata-se de um estudo exploratório, descritivo e estudo de caso. Sendo assim, para se alcançar o objetivo desta pesquisa, foi adotada uma tipologia descrita por Raupp e Beuren (2006), e Vergara (2016), aplicada a estudos sociais aplicados. Quanto aos fins, portanto, é caracterizado como exploratório, pois devido a relevância destas discussões, o intuito 
aqui é trabalhar, cluster, capital social e redes de relacionamento em nível regional, ainda pouco explorado, contribuindo com as abordagens já existentes na literatura vigente. Sampieri, Collado, Lucio (2013), e Richardson (2014), afirmam que o estudo exploratório só é caracterizado desta forma, quando se deseja explorar de uma melhor forma o problema, e que neste sentido conhecer melhor o objeto estudado é uma possibilidade.

Entende-se que esta abordagem é apropriada para um estudo exploratório cujo foco é compreender mais profundamente como as empresas do cluster se beneficiam da colaboração. É descritivo, pois descreve os benefícios gerados aos sujeitos do cluster têxtil e de confecção da região de Blumenau, a partir das relações entre as empresas e as instituições locais. Para Gil (2017), a pesquisa descritiva tem como objetivo a descrição das características de determinada população, tendo como finalidade a identificação das possíveis relações e benefícios entre os objetos estudados.

Estudo de caso, pois se utiliza de empresas e instituições localizadas no cluster têxtil e de confecção da região de Blumenau. O universo ou o corpo de análise da pesquisa é toda a estrutura das empresas e instituições, e a amostra se concentra na análise dos benefícios gerados aos sujeitos do cluster têxtil, a partir das relações entre as empresas e as instituições locais. Segundo dados da Associação Brasileira da Indústria Têxtil (ABIT, 2018), a cadeia têxtil e de confecções no Brasil, é o segundo maior empregador da indústria de transformação e maior gerador do primeiro emprego. A cadeia é formada por 27,5 mil empresas formais, responsáveis por 1,5 milhão de empregados diretos e 8 milhões se considerados os indiretos, dos quais $75 \%$ são de mão de obra feminina (Figura 2).

Figura 2 - Estrutura do cluster têxtil e de confecção da região de Blumenau

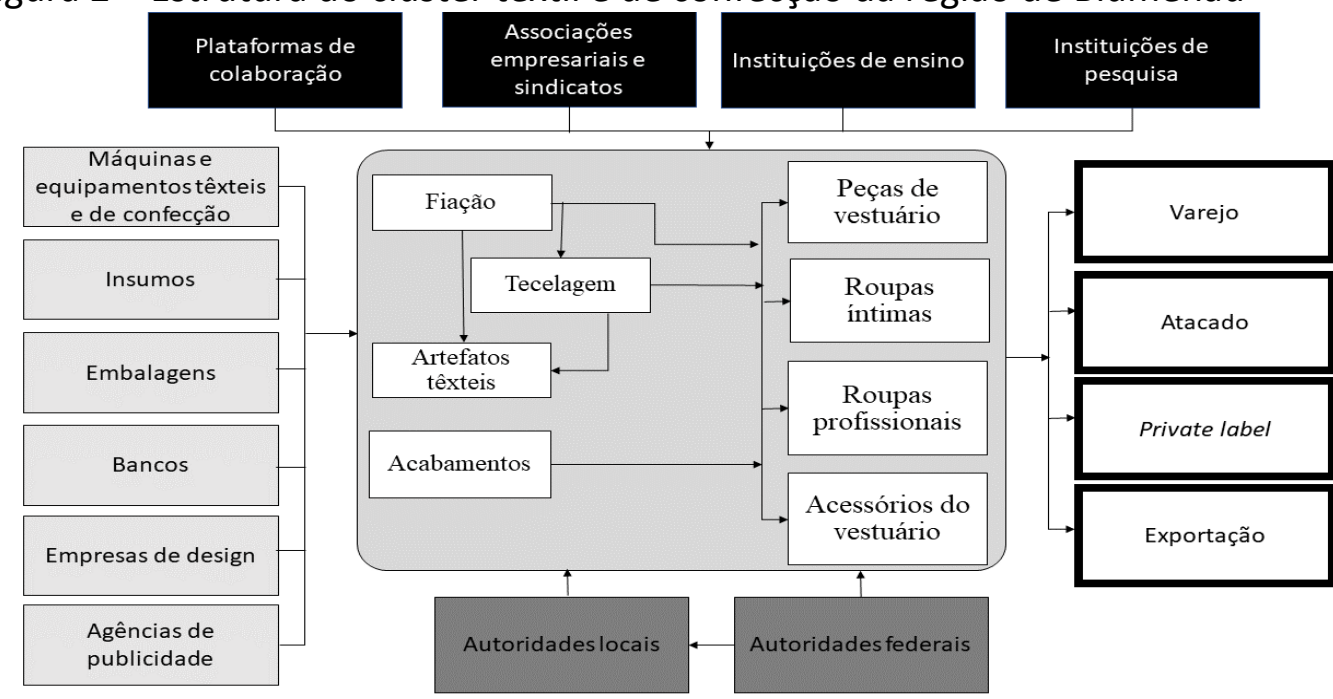

Fonte: Adaptado de Damiano Lepori e Philippe Gugler (2016). 
O cluster têxtil e de confecção é cercado por numerosas organizações / instituições ligadas, que contribuem para a vantagem competitiva do agrupamento. As instituições podem ser divididas em quatro categorias principais: 1) as plataformas de colaboração, 2) as associações empresariais, 3) as instituições de ensino, e 4) as instituições de pesquisa.

As empresas pertencentes ao cluster foram selecionados de acordo com os seguintes códigos da Classificação Nacional de Atividades Econômicas (CNAE), descritos no quadro 1:

Quadro 1 - Grupos selecionados do CNAE para o cluster

\begin{tabular}{|c|c|c|}
\hline GRUPO & CÓDIGO & DESCRIÇÃO \\
\hline \multirow[t]{5}{*}{13 FABRICAÇÃO DE PRODUTOS TÊXTEIS } & 13.1 & Preparação e fiação de fibras têxteis \\
\hline & 13.2 & Tecelagem, exceto malha \\
\hline & 13.3 & Fabricação de tecidos de malha \\
\hline & 13.4 & $\begin{array}{l}\text { Acabamentos em fios, tecidos e artefatos } \\
\text { têxteis }\end{array}$ \\
\hline & 13.5 & $\begin{array}{l}\text { Fabricação de artefatos têxteis, exceto } \\
\text { vestuário }\end{array}$ \\
\hline \multirow{4}{*}{$\begin{array}{l}14 \text { CONFECÇÃO DE ARTIGOS DO VESTUÁRIO } \\
\text { E ACESSÓRIOS }\end{array}$} & $14.11-8$ & Confecção de roupas íntimas \\
\hline & $\underline{14.12-6}$ & $\begin{array}{l}\text { Confecção de peças de vestuário, exceto } \\
\text { roupas íntimas }\end{array}$ \\
\hline & $14.13-4$ & Confecção de roupas profissionais \\
\hline & $\underline{14.14-2}$ & $\begin{array}{l}\text { Fabricação de acessórios do vestuário, } \\
\text { exceto para segurança e proteção }\end{array}$ \\
\hline $\begin{array}{l}\text { 17 FABRICAÇÃO DE CELULOSE, PAPEL E } \\
\text { PRODUTOS DE PAPEL }\end{array}$ & $\underline{17.3}$ & $\begin{array}{l}\text { Fabricação de embalagens de papel, } \\
\text { cartolina, papel-cartão e papelão ondulado }\end{array}$ \\
\hline 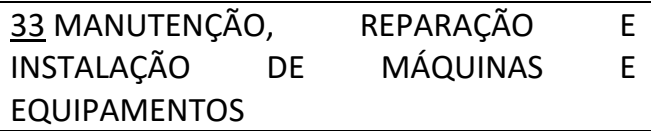 & 33.2 & Instalação de máquinas e equipamentos \\
\hline
\end{tabular}

Fonte: Instituto Brasileiro de Geografia e Estatística (2019).

A seleção dos sujeitos deu-se de modo intencional, por homogeneidade, que significa a escolha de participantes que experimentam o fenômeno central ou conceito-chave, sendo estes sujeitos membros de um subgrupo com características distintas (CRESWELL, 2010). Nesta pesquisa, os gestores entrevistados atuam em diversas empresas do segmento têxtil conforme apresentado no quadro 2 .

A técnica utilizada foi a análise de conteúdo. Categorias e subcategorias foram classificadas durante o processo de análise de dados, de forma a cobrir todas as unidades temáticas identificadas nas entrevistas e questionários. 
Quadro 2 - Sujeitos da pesquisa

\begin{tabular}{|c|c|c|c|c|c|c|}
\hline 을 & 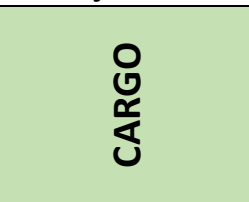 & 岩 & $\begin{array}{l}\text { 을 } \\
\text { F }\end{array}$ & 岁 & 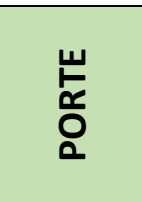 & 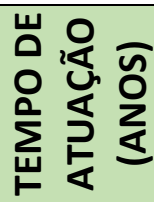 \\
\hline 1 & Diretor & $\begin{array}{c}\text { Instalação de máquinas } \\
\text { e equipamentos }\end{array}$ & Fornecedor & Blumenau & Pequeno & 13 \\
\hline 2 & $\begin{array}{c}\text { Gerente } \\
\text { Administrativo }\end{array}$ & $\begin{array}{c}\text { Instalação de máquinas } \\
\text { e equipamentos }\end{array}$ & Fornecedor & Blumenau & Pequeno & 13 \\
\hline 3 & $\begin{array}{l}\text { Coordenador de } \\
\text { Serviços ao } \\
\text { cliente }\end{array}$ & $\begin{array}{c}\text { Fabricação de } \\
\text { embalagens de papel, } \\
\text { cartolina, papel-cartão } \\
\text { e papelão ondulado }\end{array}$ & Fornecedor & Blumenau & Médio & 40 \\
\hline 4 & Diretor & $\begin{array}{c}\text { Confecção de roupas } \\
\text { íntimas }\end{array}$ & Fabricante & Gaspar & Pequeno & 10 \\
\hline 5 & $\begin{array}{l}\text { Superintende } \\
\text { regional }\end{array}$ & Ensino técnico & $\begin{array}{l}\text { Instituição } \\
\text { de ensino }\end{array}$ & Blumenau & Grande & 8 \\
\hline
\end{tabular}

Fonte: Dados da pesquisa (2019).

Nesse sentido, foram selecionadas categorias identificadas na literatura, que apontam os benefícios das relações entre empresas e instituições em um cluster, para nortear as perguntas aos entrevistados, conforme quadro 3.

Quadro 3 - Categorias do capital social

\begin{tabular}{|c|c|}
\hline $\begin{array}{l}\text { DIMENSÃO DO } \\
\text { CAPITAL SOCIAL }\end{array}$ & BENEFÍCIOS \\
\hline Estrutural & $\begin{array}{l}\text { Mão-de-obra qualificada } \\
\text { Acesso facilitado a fornecedores/insumos (localização) } \\
\text { Compartilhamento de infraestrutura logística } \\
\text { Inovação } \\
\text { Acesso a mercados externos } \\
\text { Melhoria da imagem/reputação } \\
\text { Acesso a cursos e treinamentos especializados }\end{array}$ \\
\hline Relacional & $\begin{array}{l}\text { Indicações de clientes / fornecedores potenciais } \\
\text { Acesso a informações de outras empresas para fins de comparação (benchmarking) } \\
\text { Compartilhamento do conhecimento (por exemplo, integração entre a universidade e } \\
\text { a empresa) }\end{array}$ \\
\hline Cognitiva & $\begin{array}{l}\text { Promoção de políticas comerciais favoráveis ao cluster } \\
\text { Atuação como um corpo de especialistas que fornece conselhos e ideias sobre } \\
\text { problemas políticos ou econômicos específicos do cluster } \\
\text { Melhoria da infraestrutura logística } \\
\text { Redução de tributos } \\
\text { Incentivos a universidades e Centros de Pesquisa e Desenvolvimento } \\
\text { Organização de eventos comerciais, como Feiras e afins. } \\
\text { Coordenação de ações contra a falsificação de produtos. } \\
\text { Oferta de uma plataforma de colaboração entre as empresas do cluster. } \\
\text { Consultoria jurídica para seus membros em propósitos específicos. } \\
\text { Negociações com sindicatos patronais } \\
\text { Garantia de uma alta conformidade entre os programas de treinamento oferecidos } \\
\text { pelas instituições de ensino e as expectativas das empresas. }\end{array}$ \\
\hline
\end{tabular}

Fonte: Dados da pesquisa (2019). 
Essas categorias servirão como apoio na análise das falas dos entrevistados. Após as exposições dos procedimentos metodológicos, a seção seguinte apresenta a análise e a discussão dos resultados.

\section{Análise e discussão dos resultados}

Praticamente todas as empresas pesquisadas apontaram como um dos principais benefícios de fazer parte do cluster a disponibilidade de mão-de-obra qualificada, como pode ser visto nos depoimentos a seguir. O fato de grandes empresas, com mais de 80 anos de tradição estarem presentes no cluster é um fator importante para explicar a qualificação da mão-de-obra, uma vez que os ofícios relacionados ao segmento são transmitidos de geração em geração.

A região dispõe de mão-de-obra qualificada através do Senai na formação de técnicos e de modelistas (sujeito 1).

Por ser uma região com várias empresas, as pessoas buscam qualificação (sujeito 4).

Diante das falas, a ideia de Porter (1998), de que é possível melhorar o desempenho das empresas e de todo seu contexto, à medida que se há mão-de-obra qualificada é validada. Além dos fabricantes de produtos têxteis e de confecção, fornecedores também podem se beneficiar da qualificação da mão-de-obra, como por exemplo, prestadores de serviços de instalação e manutenção de equipamentos:

Técnicos de manutenção de máquinas têxteis dispensados pelas indústrias podem ser contratados por nossa empresa já tendo uma boa experiencia na área (sujeito 2).

Outro benefício apontado por um fabricante de produtos de confecção foi o acesso facilitado a fornecedores/insumos:

Os fornecedores têm mais iniciativa, promovendo feiras que se localizam próximo a região onde a maioria das empresas estão localizadas, facilitando acesso (sujeito 4).

Quanto a este acesso facilitado, Granovetter já destacava lá em 1992, que em se tratando de capital social, o acesso a recursos por parte de um fabricante de produtos de confecção, se dá por meio de relações sociais. A cidade Blumenau sedia a cada dois anos a Feira Brasileira para a Indústria Têxtil (FEBRATEX), apresentando os últimos lançamentos de máquinas, materiais e tecnologias para a indústria têxtil. O evento reúne os principais segmentos da cadeia têxtil: desde máquinas de costura, máquinas de corte, aviamentos, etiquetas, embalagens, equipamentos, acabamentos, beneficiamentos, fios, estamparias, automação industrial, informática, até teares 
e matérias-primas (FEBRATEX, 2018) e impulsiona os negócios das empresas, como pode ser visto no seguinte depoimento do fornecedor de equipamentos:

A feira impulsiona os negócios, o pessoal vem de fora conhecer as novidades, sempre ajuda. A procura ocorre tanto pelas empresas da região, como pelo pessoal que vêm de fora (sujeito 2).

O compartilhamento da infraestrutura logística pelas empresas da região, é um benefício que poderia ser mais bem explorado, do ponto de vista do entrevistado, fornecedor de embalagens:

O compartilhamento de infraestrutura logística pode ser relacionado ao modal de transporte da região. Apesar de muitos serem dedicados as empresas, o compartilhamento seria uma via interessante de trabalho (Sujeito 3).

Já o compartilhamento de conhecimento e informação pode ocorrer tanto na relação cliente-fornecedor, como entre empresas, por meio da Associação Empresarial, conforme depoimentos abaixo.

A gente pode avaliar como é que tá a produção da empresa, sugestões de coisas que a gente viu em outras empresas, de como deveria funcionar pelo software e como realmente está a empresa, ter ideia de como deveria ser a produção, quando deveria estar produzindo, se não está produzindo aquilo é porque deve ter algum problema no processo. Às vezes uma modificação que é feita numa máquina para atender a um cliente de outro país, acaba vindo pra cá também (sujeito 2).

Algumas fontes de troca de conhecimento são os núcleos de inovação através da ACIB (sujeito 1).

O compartilhamento de conhecimento poderia ser nas ferramentas de gestão e no aperfeiçoamento das atividades inerentes a administração das corporações (sujeito 3).

Dessa forma, legitimando o que foi dito até aqui, quanto ao compartilhamento de conhecimento e informações, Granovetter (1985), destaca que há momentos informais e formais para os fluxos de informações, e que estes fluxos podem ocorrer por meio de reuniões, eventos, dentre outras formas. Isso reflete na fala do sujeito 4 e 1, quando se trata de inovação.

O Sesi está sempre nos atualizando na parte de segurança (sujeito 4).

Cursos e treinamentos dirigidos na ACIB (sujeito 1).

Empresas localizadas em um cluster também têm acesso a cursos e treinamentos especializados. Os depoimentos abaixo corroboram a literatura.

Nossa empresa realiza palestras e treinamentos para a formação de instrutores, qualificando professores da FURB - Universidade Regional de Blumenau que dão aula de sistemas de corte (sujeito 1). 
A FURB ganha o equipamento em comodato. Enquanto eles estiverem dando treinamento o equipamento é deles, o dia que eles não quiserem mais utilizar eles devolvem, mas não tem custo pra eles. Eles têm equipamento e software sem custo, a manutenção muitas vezes não é cobrada, quando cobrado é um valor baixo, pra que eles possam aplicar treinamentos. Os treinamentos que nós fornecemos aos professores para repassarem o conhecimento também não são cobrados. (sujeito 2).

O SENAI oferece vários cursos com desconto para as indústrias. Além dos Cursos do MDIMelhoria de Desempenho Industrial, tem divulgações de outros cursos (sujeito 4).

Neste caso, vale destacar, que fazendo parte da Tríplice Hélice, os acessos aos recursos e os laços citados por Granovetter (1992), com outras instituições, permitem a estas instituições possibilidades de acesso a recursos tais como treinamentos especializados, além de informações. Sendo assim, há também falas que relatam sobre a indicação de clientes bem como de fornecedores potenciais, nestas relações. Isso pode ser observado na fala do sujeito 3 e 2 a seguir.

O bom relacionamento também propicia a melhora da divulgação e o fomento dos bons parceiros. Importante para a obtenção de bons clientes e fornecedores (Empresário).

O dono da empresa trabalhava numa grande indústria têxtil da região. Após ter saído dessa indústria, para trabalhar na empresa de representação de máquinas para confecção da família, recebeu a informação por meio de um dos antigos colegas de que havia uma indústria norte americana que estava procurando um representante no Brasil. Assim, a indústria indicou a empresa para representar equipamentos destinados à indústria da confecção, principalmente nas áreas de corte e bordado, gerando uma nova empresa (sujeito 2).

A proximidade às empresas têxteis de confecção, contato direto com os proprietários, indicações de clientes potenciais. Quando não é indicação, é comentado na empresa que já tem equipamento em alguma outra empresa do ramo que eles conhecem e se interessam pelo equipamento também. Como é tudo aqui perto, fica fácil de eles visitarem a empresa, conhecer o equipamento... fica fácil para prestar o serviço, porque está tudo aqui próximo (sujeito 2).

Acesso às informações de outras empresas para fins de comparação (benchmarking), melhoria da imagem/reputação e acesso aos mercados externos não foram citados. Portanto, segundo Granovetter (1992), os elementos que explicam o relacionamento existente nestas redes de relacionamento, vão ao encontro do que a teoria de capital social coloca como principais fatores: confiança, diversidade de rede (estrutural), tamanho da rede e diversidade demográfica.

Os resultados da pesquisa são apresentados no quadro 3. 
Quadro 4 - Relação entre a teoria e os achados da pesquisa

\begin{tabular}{|c|c|c|c|}
\hline OBJETIVO & TEORIA & DIMENSÕES & $\begin{array}{c}\text { EVIDÊNCIAS (BENEFÍCIOS } \\
\text { IDENTIFICADOS) }\end{array}$ \\
\hline \multirow{3}{*}{$\begin{array}{l}\text { Compreender os } \\
\text { benefícios } \\
\text { gerados entre os } \\
\text { sujeitos que } \\
\text { compõem o } \\
\text { cluster têxtil de } \\
\text { Blumenau, nas } \\
\text { dimensões } \\
\text { estrutural, } \\
\text { relacional e } \\
\text { cognitiva do } \\
\text { capital social }\end{array}$} & \multirow{3}{*}{$\begin{array}{l}\text { Capital } \\
\text { Social }\end{array}$} & $\begin{array}{l}\text { Estrutural } \\
\text { P1 - Empresas inseridas } \\
\text { em um cluster possuem } \\
\text { acesso facilitado às } \\
\text { estruturas disponíveis no } \\
\text { ambiente, como mão-de- } \\
\text { obra qualificada, } \\
\text { fornecedorese } \\
\text { infraestrutura logística. }\end{array}$ & $\begin{array}{l}\text { Disponibilidade de mão-de-obra qualificada } \\
\text { Acesso facilitado a fornecedores/insumos } \\
\text { Inovação } \\
\text { Acesso a cursos e treinamentos } \\
\text { especializados }\end{array}$ \\
\hline & & $\begin{array}{l}\text { Relacional } \\
\text { P2 - Empresas que } \\
\text { possuem relaciona-mento } \\
\text { com institui-ções locais } \\
\text { possuem acesso facilitado } \\
\text { a indicações de clientes e } \\
\text { fornecedores, além do } \\
\text { compartilhamento de } \\
\text { conhecimento } \\
\text { aconselhamento técni-co e } \\
\text { jurídico, fomen-tando a } \\
\text { inovação. }\end{array}$ & $\begin{array}{l}\text { Indicações de clientes / fornecedores } \\
\text { potenciais, principalmente em feiras } \\
\text { especializadas } \\
\text { Compartilhamento do conhecimento } \\
\text { (empresa-universidade, empresa-instituições, } \\
\text { núcleo de inovação da ACIB) }\end{array}$ \\
\hline & & $\begin{array}{l}\text { Cognitiva } \\
\text { P3 - Empresas que } \\
\text { possuem relaciona-mento } \\
\text { com insti-tuições locais } \\
\text { bene-ficiam-se de ações } \\
\text { coletivas para de- } \\
\text { senvolvimento e pro- } \\
\text { moção do cluster. }\end{array}$ & $\begin{array}{l}\text { Organização de eventos comerciais, como } \\
\text { Feiras e afins } \\
\text { Garantia de uma alta conformidade entre os } \\
\text { programas de treinamento oferecidos pelas } \\
\text { instituições de ensino e as expectativas das } \\
\text { empresas }\end{array}$ \\
\hline
\end{tabular}

Fonte: Dados da pesquisa (2019).

Sendo assim, diante destes dados, pode-se inferir que o capital social reside nas relações entre os nós e assim como o capital físico e humano facilita a atividade produtiva, o capital social também possui um importante papel, podendo ser visto claramente neste estudo sobre o cluster têxtil blumenauense (COLEMAN, 1988).

A dimensão do capital social que apresenta maior oportunidade de aprimoramento é a dimensão cognitiva. Contribuições importantes das instituições locais citadas na literatura, como por exemplo, a função de conselheiros jurídicos e econômicos para o cluster, a interferência política para melhoria da infraestrutura logística, redução de tributos e incentivos a universidades e Centros de Pesquisa e Desenvolvimento, a coordenação de ações contra a falsificação e a oferta de uma plataforma de colaboração entre as empresas do cluster, não foram citados pelos sujeitos entrevistados. 


\section{Considerações finais}

Essa pesquisa buscou na teoria do capital social a base para compreender os benefícios gerados entre os sujeitos que compõem o cluster têxtil de Blumenau, nas dimensões estrutural, relacional e cognitiva. A investigação realizada permitiu responder algumas perguntas. A primeira delas, é a pergunta que norteia a pesquisa: como as dimensões estrutural, relacional e cognitiva do capital social geram benefícios para os sujeitos que compõem o cluster têxtil de Blumenau? As entrevistas realizadas permitiram associar os principais componentes das dimensões estrutural, relacional e cognitiva, com os seus respectivos benefícios.

De maneira geral, a dimensão estrutural é a mais consolidada no cluster pesquisado e consequentemente o que oferece maiores vantagens aos membros do cluster, principalmente em relação à mão-de-obra. A concentração de indústrias tradicionais na região facilita a transmissão dos ofícios de geração em geração. Além disso, a região de Blumenau está muito bem-servida com cursos de graduação e especialização, como Moda, Negócios do vestuário e Engenharia têxtil, além de diversos cursos técnicos e profissionalizantes para o segmento.

O principal destaque da dimensão relacional foi o compartilhamento de conhecimentos promovidos pelas instituições de ensino da região e pelas associações empresariais, confirmando o papel dessas instituições como mecanismos importantes para estimular a cooperação entre firmas para maior competitividade. Outrossim, vale ressaltar a importância da propaganda bocaa-boca, que promove indicações de clientes/fornecedores potenciais. A última dimensão destaca novamente a importância das instituições locais para o atendimento dos interesses coletivos do cluster. Na dimensão cognitiva, a promoção de eventos comerciais, é considerado o maior benefício. Por exemplo, Blumenau sedia vários eventos voltados ao segmento, incluindo a maior Feira das Américas para a Indústria têxtil e de confecção.

Por outro lado, o resultado dessa pesquisa, mostrou uma grande oportunidade de as instituições locais ampliarem sua atuação em diversas frentes de trabalho. Evidentemente, essa afirmação é baseada somente nas falas dos entrevistados, que não relataram várias contribuições de instituições locais para o cluster identificadas na literatura. No entanto, essa falta de relatos pode servir como um alerta, seja para ampliar o leque de serviços ofertados ao cluster, seja para melhorar a divulgação de serviços já prestados.

Sendo assim, a principal contribuição teórica deste estudo está na análise de um cluster sob a lente da teoria do capital, no que diz respeito às suas três dimensões. Ainda, contribui com a literatura de cluster ao identificar os benefícios gerados pelo capital social e pelas 
externalidades geradas no cluster têxtil de Blumenau, mapeando as relações entre empresas e instituições do cluster.

Como contribuição social, o estudo visa mostrar à sociedade civil que as formas de relacionamento e os benefícios gerados ao cluster têxtil e de confecção pelo seu capital social ajudam a melhorar o desenvolvimento regional. Finalmente, o estudo contribui para que gestores das empresas e instituições do cluster avaliem oportunidades de fortalecimento das relações e possíveis ganhos por meio do cluster, principalmente na dimensão cognitiva. Nossa principal limitação foi o baixo número de empresários e representantes que se colocaram à disposição para a pesquisa. No entanto, ainda assim, tivemos representantes dos agentes mais importantes do cluster, como clientes, fornecedores de insumos, prestadores de serviço e instituições de ensino.

Sugere-se, por fim, que as dimensões do capital social sejam utilizadas em pesquisas em outras regiões do Brasil, para possibilitar a comparação dos resultados e compartilhamento de boas práticas para empresas do segmento têxtil. Esse tipo de estudo também pode ser ampliado para outros tipos de clusters.

\section{Referências}

ARAGÓN, C. et al. A social capital approach for network policy learning: The case of an established cluster initiative. European Urban and Regional Studies, v. 21, n. 2, p. 128-145, 2014.

COLEMAN, J. S. Social capital in the creation of human capital. American journal of sociology, v. 94, p. S95-S120, 1988.

CHEN, S.-T.; HAGA, K. Y. A.; FONG, C. M. The effects of institutional legitimacy, social capital, and government relationship on clustered firms' performance in emerging economies. Journal of Organizational Change Management, v. 29, n. 4, p. 529-550, 2016.

CRESWELL, J. W. Projeto de pesquisa: métodos qualitativo, quantitativo e misto. Porto Alegre: Artmed: Bookman, 2010.

DE MELO, P. T. N. B.; REGIS, H. P.; VAN BELLEN, H. M. Princípios epistemológicos da teoria do capital social na área da administração. Cadernos EBAPE. BR, v. 13, n. 1, p. 136-164, 2015.

ELVEKROK, I. et al. Firm innovation benefits from regional triple-helix networks. Regional Studies, v. 52, n. 9, p. 1214-1224, 2018.

ETZKOWITZ, H.; LEYDESDORFF, L. The dynamics of innovation : from National Systems and “" Mode 2 "' to a Triple Helix of university - industry - government relations. Science And Technology, v. 29, n. 2, p. 109-123, 2000.

FARIA, J. R. Location Clusters, FDI and Local Entrepreneurs: Consistent Public Policy. Journal of the Knowledge Economy, v. 7, n. 4, p. 858-868, 2016. 
FARINA, M. C. et al. Análise de redes sociais no Arranjo Produtivo Local dos ramos têxtil e de confecções da região da grande São Paulo a partir de uma visão de governança. Gestão \& Regionalidade, v. 33, n. 98, p. 36-52, 2017.

GRESS, D. R. Cluster considerations and Korean subsidiaries in the US. GeoJournal, v. 76, n. 6, p. 661-673, 2011.

GRANOVETTER, M. Problems of explanation in economic sociology. In: NOHRIA, N. Nohria; ECLES, R. G. (Eds.). Networks and organization: structure, form and action. Boston: HBS Press, 1992. p. 25-56.

GRANOVETTER, M. Economic action and social structure: the problem of embeddedness. American Journal of Sociology, v. 91, n. 3, p. 481-510, 1985.

LINDQVIST et al. The Cluster Initiative Greenbook 2.0. Stockholm: Ivory Tower Publishers, 2013.

MATHEWS, M. Managing local supplier networks: conflict or compromise? Regional Studies, v. 52, n. 7, p. 890-900, 2018.

MOLINA-MORALES, F. X.; MARTÍNEZ-CHÁFER, L. Cluster Firms : You' II Never Walk Alone. n. October, p. 37-41, 2014.

MONDINI, V. E. D.; AMAL, M.; GOMES, G. Influência dos recursos do cluster no desempenho inovador de empresas têxteis. BASE - Revista de Administração e Contabilidade da Unisinos, v. 13, n. 4, p. 279-293, 2016.

NALEBUFF, B. J.; BRANDENBURGER, A. M. Co-opetição. Rio de Janeiro: Rocco, 1996.

NAHAPIET, J.; GHOSHAL, S. Social capital, intellectual capital, and the organizational advantage. Academy of Management Review, v. 23, n. 2, p. 242-266, 1998.

NEWBERY, R. et al. Sustaining business networks: Understanding the benefit bundles sought by members of local business associations. Environment and Planning C: Government and Policy, v. 34, n. 7, p. 1267-1283, 2016.

PITTAWAY, L. et al. Networking and innovation: a systematic review of the evidence 200. International Journal of Management Reviews, v. 5-6, n. 3-4, p. 137-168, 2004.

PORTER, M. E. Clusters and the New Economics of Competition. Harvard Business Review, n. November-December, 1998.

RODRIGUES, M. A. et al. Identificação e análise espacial das aglomerações produtivas do setor de confeç̧ões na região Sul. Economia Aplicada, v. 16, n. 2, p. 311-338, 2012.

SÖLVELL, Ö.; LINDQVIST, G.; KETELS, C. The Cluster Initiative Greenbook Foreword by. [s.I.] Ivory Tower Publishers, 2003.

SÖLVELL, Ö.; WILLIAMS, M. Building the Cluster Commons. Stockholm: Ivory Tower Publishers, 2013.

SOHN, A. P. L. et al. Aprendizagem interorganizacional: estudo sobre os canais de transmissão de conhecimento em clusters têxteis e de vestuário no Brasil e em Portugal. Revista Alcance, v. 21, n. 4, p. 777-796, 2014.

TSAI, W.; GHOSHAL, S. Social capital and value creation: The role of intrafirm networks. Academy of management Journal, v. 41, n. 4, p. 464-476, 1998.

VICEDO, J. C.; VICEDO, J. C. Industrial Clusters, Innovation and Universities - The Role of the University in a Textile Cluster. International Journal of Business and Social Science, v. 2, n. 8, p. 
267-275, 2011. 